\title{
Effects of Levosimendan on Hydrogen Peroxide Induced Contraction in Human Saphenous Vein
}

\author{
Burak Cem Soner $^{1}$, Ayse Saide Sahin ${ }^{1 *}$, Ipek Duman ${ }^{2}$, Niyazi Gormus ${ }^{3}$ \\ ${ }^{1}$ Department of Pharmacology, Meram Faculty of Medicine, Selcuk University, Konya, Turkey; ${ }^{2}$ Pharmacology, Ministry of Health, \\ Konya, Turkey; ${ }^{3}$ Department of Cardiovascular Surgery, Meram Faculty of Medicine, Selcuk University, Konya, Turkey. \\ Email: ${ }^{*}$ aysesaide@gmail.com
}

Received May $30^{\text {th }}, 2011$; revised July $28^{\text {th }}, 2011$; accepted August $5^{\text {th }}, 2011$.

\begin{abstract}
Aim: Increased oxidative stress plays important roles in vascular dysfunction in patients undergoing coronary artery bypass graft surgery. Hydrogen peroxide $\left(\mathrm{H}_{2} \mathrm{O}_{2}\right)$ is used as an experimental model for oxidative stress. The present study was designed to assess the effects of levosimendan pretreatment on the contractile effects induced by $\mathrm{H}_{2} \mathrm{O}_{2}$ in human saphenous vein (HSV) segments. Methods: We studied $\mathrm{H}_{2} \mathrm{O}_{2}$ induced contractions of isolated HSV mounted in standard tissue baths. $\mathrm{H}_{2} \mathrm{O}_{2}\left(10^{-6}-10^{-3} \mathrm{M}\right)$ was added cumulatively to the organ bath. Concentration-response curves to $\mathrm{H}_{2} \mathrm{O}_{2}$ were repeated in the presence of levosimendan $\left(10^{-8} \mathrm{M}\right)$. In the second series of experiments, strips were contracted with 5-HT $\left(10^{-5} M\right)$. When the contraction reached a stable plateau, $\mathrm{H}_{2} \mathrm{O}_{2}$ was administrated cumulatively into the organ bath. The same procedure was conducted in the presence of levosimendan. Results: Pretreatment of the SV strips with levosimendan significantly reduced the contractile response to each concentration of $\mathrm{H}_{2} \mathrm{O}_{2}$. 5-HT produced contractions in $\mathrm{SV}$ strips. Further treatment of these strips with $\mathrm{H}_{2} \mathrm{O}_{2}$ resulted in statistically significant concentration-dependent increases in tension. Preincubation of the tissues with levosimendan did not significantly influence the maximum amplitude of the 5-HT-induced tone but inhibited the contractile effect of $\mathrm{H}_{2} \mathrm{O}_{2}$ on the 5-HT-induced contraction. Conclusion: Pretreatment of HSV with clinical concentrations of levosimendan inhibits the vasoconstriction caused by oxidative stress, indicating its potential preventive effect against oxidative stress induced graft spasm.
\end{abstract}

Keywords: Hydrogen Peroxide, Human Saphenous Vein, Levosimendan

\section{Introduction}

Human saphenous vein is frequently used for coronary artery bypass grafting because of ready availability and suppleness [1]. Vasospasm of the graft following coronary artery bypass graft $(\mathrm{CABG})$ surgery is a major problem and may cause perioperative and late failure of bypass conduits. There are ongoing researches on determining the mechanisms causing vasospasm and various vasodilators have been studied to prevent or reverse vasoconstriction in various grafts $[2,3]$.

Increased oxidative stress plays important roles in myocardial and vascular dysfunction in patients undergoing CABG [4]. Hydrogen peroxide $\left(\mathrm{H}_{2} \mathrm{O}_{2}\right)$ is an important derivative of oxidative metabolism and is a major contributor in oxidative stress-induced functional and metabolic dysfunction [5]. Although generation of $\mathrm{H}_{2} \mathrm{O}_{2}$ may occur under normal physiological conditions and is not restricted to pathological conditions, its formation in the endothelium of blood vessels under stress conditions such as diabetes, hypertension, preeclampsia and extracorporeal membrane oxygenation holds an important place in CABG surgery [6]. $\mathrm{H}_{2} \mathrm{O}_{2}$ is already used as an experimental model for oxidative stress and it has been shown to induce concentration dependent increases in contraction in various blood vessels including saphenous veins $[7,8]$ and potentiates the effects of vasoconstrictor agents [9].

Levosimendan is a new cardiac enhancer that exerts positive inotropic effects on heart failure by calcium sensitization of contractile proteins. Recent research has displayed that levosimendan also causes peripheral vasodilatation and may also have antioxidant properties [10]. The present study was designed to assess the effects of levosimendan pretreatment on the contractile effects of $\mathrm{H}_{2} \mathrm{O}_{2}$ in human saphenous vein (HSV) segments.

\section{Methods}

The study was approved by the ethics committee of Selcuk University, Meram Faculty of Medicine and in- 
formed consent was obtained from all patients undergoing myocardial revascularization surgery. The discarded HSV segments were placed in cold Krebs-Henseleit solution (KHS: $\mathrm{NaCl} 119 \mathrm{mmol} / \mathrm{L}, \mathrm{KCl} 4.7 \mathrm{mmol} / \mathrm{L}$, $\mathrm{MgSO}_{4} 1.5 \mathrm{mmol} / \mathrm{L}, \mathrm{KH}_{2} \mathrm{PO}_{4} 1.2 \mathrm{mmol} / \mathrm{L}, \mathrm{CaCl}_{2} 2.5$ $\mathrm{mmol} / \mathrm{L}, \mathrm{NaHCO}_{3} 25 \mathrm{mmol} / \mathrm{L}$, and glucose $11 \mathrm{mmol} / \mathrm{L}$ ) and transported to the laboratory for the study in $20 \mathrm{~min}$ utes. After removal of the surrounding tissue, vein segments were cut into helical $12-15 \mathrm{~mm}$ strips and suspended in a $20 \mathrm{ml}$ organ bath containing $\mathrm{KHS}$ at $37^{\circ} \mathrm{C}$ and continuously bubbled with $95 \% \mathrm{O}_{2}$ and $5 \% \mathrm{CO}_{2}$ gas mixture. Tissues were gradually stretched to a basal resting tension of $1.0 \mathrm{~g}$ and were allowed to equilibrate to their own resting tension for 60 minutes, and during this period the KHS was changed every 15 minutes.

After an equilibration period, strips $(n=8)$ were contracted using $10^{-5} \mathrm{M}$ serotonin (5-HT). To standardize responses between strips, once maximal 5-HT contractions were recorded and used as a standard by which subsequent contractions of the tissue could be expressed (as a percentage of this contraction).

Two types of experiment were performed. In the first set of experiments, the effect of $\mathrm{H}_{2} \mathrm{O}_{2}$ was investigated in levosimendan-pretreated strips $(\mathrm{n}=8)$. First the maximum contractions to 5-HT $(10-5 \mathrm{M})$ were recorded in HSV strips. Tissues were then washed twice within 15 minutes of washout intervals and thereafter concentration-response curves to cumulative $\mathrm{H}_{2} \mathrm{O}_{2}\left(10^{-6}-10^{-3} \mathrm{M}\right)$ were recorded. After two 15 minutes of washout intervals concentration-response curves to cumulative $\mathrm{H}_{2} \mathrm{O}_{2}\left(10^{-6}\right.$ $\left.10^{-3} \mathrm{M}\right)$ were repeated in the presence of levosimendan $\left(10^{-8} \mathrm{M}\right)$.

In the second set of experiments, the effects of levosimendan on oxidative stress caused by $\mathrm{H}_{2} \mathrm{O}_{2}$ in the tissues contracted with 5-HT were investigated. Strips $(\mathrm{n}=8)$ were contracted with 5-HT $\left(10^{-5} \mathrm{M}\right)$. When the contraction reached a stable plateau, $\mathrm{H}_{2} \mathrm{O}_{2}$ was administrated cumulatively $\left(10^{-6}-10^{-3} \mathrm{M}\right)$ into the organ baths in one$\log$ increments. The same procedure was also conducted in the presence of levosimendan $\left(10^{-8} \mathrm{M}\right)$.

In all groups, isometric recording of tension changes were obtained with force transducers (Grass FTO4; Grass Instrument $\mathrm{Co}$, W. Warwick, RI, USA) connected through amplifiers to a polygraph (Grass 7D).

The effects of $\mathrm{H}_{2} \mathrm{O}_{2}$ are expressed as the percentage of the control contractile response elicited at $10^{-5} \mathrm{M} 5$-HT. The maximum contraction $\left(\mathrm{E}_{\max }\right)$ and the concentration required to achieve $50 \%$ of maximum contraction $\left(\mathrm{EC}_{50}\right)$ were calculated for $\mathrm{H}_{2} \mathrm{O}_{2}$.

All data were expressed as mean \pm s.e. mean (SEM). The statistical significance of differences among groups was analyzed by using unpaired student's t-test. For all studies, $\mathrm{p}$ value less than 0.05 was considered significant.
All the drugs were prepared freshly at the day of the study. The following compounds were used: Hydrogen peroxide $\left(\mathrm{H}_{2} \mathrm{O}_{2}\right)$ obtained from Merck, Darmstadt, Germany; levosimendan, Simdax, from Abbott Laboratories; serotonin (5-HT) from Sigma, St. Louis, MO, USA.

\section{Results}

The effects of $\mathrm{H}_{2} \mathrm{O}_{2}\left(10^{-6}-10^{-3} \mathrm{M}\right)$ on HSV strips in the absence and presence of levosimendan are summarized in Figure 1. A maximum contraction of $32.4 \% \pm 1.12 \%$ was obtained with $\mathrm{H}_{2} \mathrm{O}_{2} 10^{-3} \mathrm{M}$ and the $\mathrm{EC}_{50}$ value was $4.6 \times 10^{-6} \pm 0.3 \mathrm{M}$. Pretreatment of the HSV strips with levosimendan $\left(10^{-8} \mathrm{M}\right)$ significantly reduced the contractile response to each one concentration of $\mathrm{H}_{2} \mathrm{O}_{2}$ (p < 0.05 ). The $\mathrm{EC}_{50}$ value for $\mathrm{H}_{2} \mathrm{O}_{2}$ was $4.5 \times 10^{-5} \pm 0.2$ and $\mathrm{E}_{\max }$ was $16.0 \% \pm 1.0 \%$ in the presence of levosimendan.

5-HT $\left(10^{-6} \mathrm{M}\right)$ produced contractions in HSV strips. Further treatment of strips with $\mathrm{H}_{2} \mathrm{O}_{2}\left(10^{-6}-10^{-3} \mathrm{M}\right)$ resulted in statistically significant concentration-dependent increases in tension $\left(\mathrm{E}_{\max }: 21.0 \pm 2.2 ; \mathrm{EC}_{50}: 2.5 \times 10^{-6} \pm\right.$ 0.17). Preincubation of the tissues with levosimendan did not significantly influence the maximum amplitude of the 5-HT-induced tone but inhibited the contractile effect of $\mathrm{H}_{2} \mathrm{O}_{2}$ on the 5-HT-induced contraction $\left(\mathrm{E}_{\max }: 2.67 \pm 0.33\right.$ ) (Figure 2).

\section{Discussion}

Results from our present in vitro model for oxidative stress shows that:

1) Pretreatment with clinical concentration of levosimendan $\left(10^{-8} \mathrm{M}\right)$ attenuates the contractile response elic-

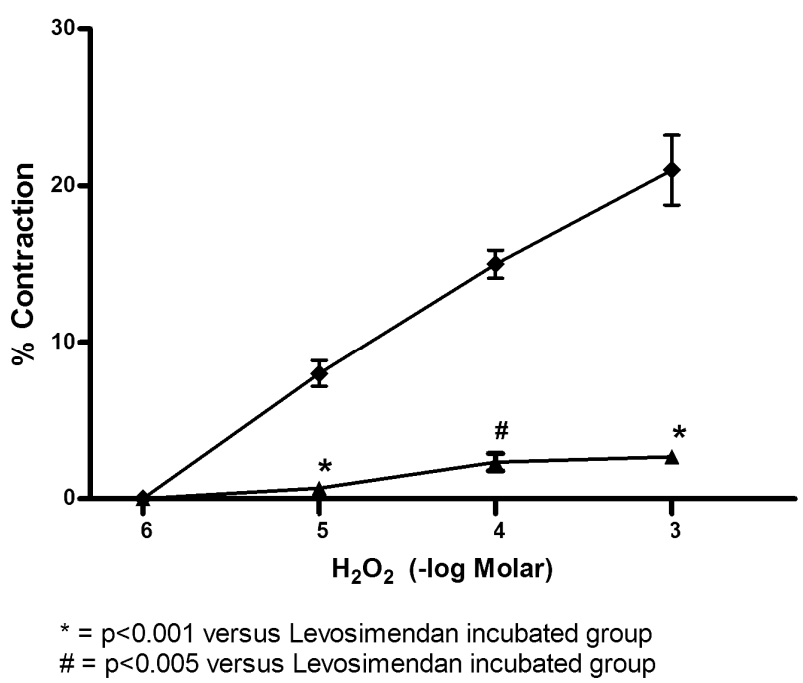

Figure 1. Concentration-response curves for contraction of HSV elicited by $\mathrm{H}_{2} \mathrm{O}_{2}$ under control conditions and after incubation with $10^{-8} \mathrm{M}$ levosimendan. Each point represents the mean \pm SEM expressed as percentage of the tension induced by $10^{-5}$ M 5-HT $(n=8)$. 


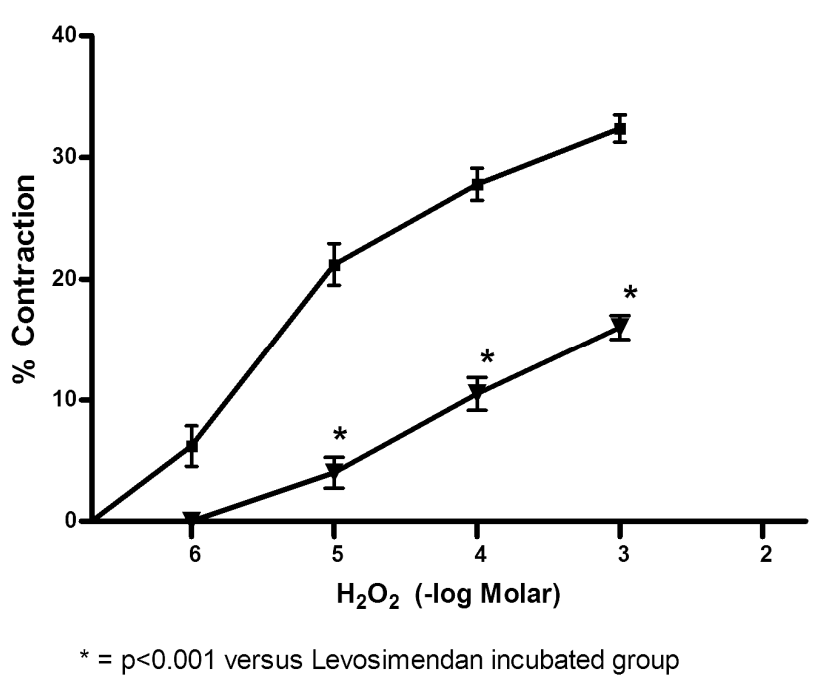

Figure 2. Concentration-response curves for $\mathrm{H}_{2} \mathrm{O}_{2}$ on the vasoconstriction induced by $10^{-5} \mathrm{M}$ 5-HT in HSV under control conditions and after incubation with $10^{-8} \mathrm{M}$ levosimendan. Each point represents the mean \pm SEM expressed as percentage of the tension induced by $10^{-5}$ M 5-HT $(n=8)$.

ited by $\mathrm{H}_{2} \mathrm{O}_{2}$.

2) Pretreatment with levosimendan $\left(10^{-8} \mathrm{M}\right)$ prevents contractile responses caused by $\mathrm{H}_{2} \mathrm{O}_{2}$ in the tissues precontracted with 5-HT but does not affect 5-HT elicited contractions.

$\mathrm{H}_{2} \mathrm{O}_{2}$ is found in the human plasma at micromolar concentrations and its concentration can increase up to millimolar levels in pathological states including myocardial ischemia and heart failure [11]. It can diffuse from its site of formation, easily crossing cell membranes and producing cellular oxidative damage [6]. However, previous studies have suggested that $\mathrm{H}_{2} \mathrm{O}_{2}$ may be an important mediator in the vasculature as a regulator of vasomotor tone [12]. In previous studies, $50 \mathrm{mM}$ to 10 $\mathrm{mM}$ concentrations of $\mathrm{H}_{2} \mathrm{O}_{2}$ were used to induce experimental oxidative stress [13-15]. In the present study, we used $10^{-6}-10^{-3} \mathrm{M}$ concentrations of $\mathrm{H}_{2} \mathrm{O}_{2}$. In order to evaluate the effect of levosimendan on vasoconstriction during oxidative stress, first we tested the effect of levosimendan with incubation on cumulative $\mathrm{H}_{2} \mathrm{O}_{2}$ concentration response curve in HSV strips at resting tension. Our results showed that the application of levosimendan inhibited contractions of $\mathrm{H}_{2} \mathrm{O}_{2}$ in HSV strips indicating its potential preventive effect against the graft spasm induced by oxidative stress. Active contraction induced by 5 -HT is considered to be an important pathological mechanism for inducing arterial spasm and may cause perioperative and late failure of bypass conduits [1]. Since $\mathrm{H}_{2} \mathrm{O}_{2}$ also potentiates contractile responses to various agents [9], after 5-HT induced contractions we evaluated the effect with the same concentration of levo- simendan incubation on cumulative $\mathrm{H}_{2} \mathrm{O}_{2}$ concentration response curve. Treatment of these strips with $\mathrm{H}_{2} \mathrm{O}_{2}$ potentiated contraction induced by 5 -HT. Levosimendan $10^{-8} \mathrm{M}$ prevented contractile responses caused by $\mathrm{H}_{2} \mathrm{O}_{2}$ in the tissues precontracted with 5-HT but does not affect 5-HT elicited contractions.

Plasma level of levosimendan during clinical practice is important to mention for proper interpretation of the experimental results. A single $0.5 \mathrm{mg}$ oral dose of levosimendan produces a peak plasma concentration of 20 $\mathrm{ng} / \mathrm{ml}(0.07$ micromol$)$ in patients with congestive heart failure [16]. Vasodilatation by levosimendan is believed to be achieved at a higher plasma concentration when compared to its positive inotropic effect. In patients with ischemic heart disease, $0.25 \mathrm{mg}$ and $0.5 \mathrm{mg}$ levosimendan increased left ventricular function, but a significant decrease in total peripheral resistance was seen only after $2 \mathrm{mg}$ and $4 \mathrm{mg}$ doses [17]. In the present study, the selected concentration $\left(10^{-8} \mathrm{M}\right)$ of levosimendan is elected as used for its inotropic effect. This concentration, which significantly inhibited the contractions to $\mathrm{H}_{2} \mathrm{O}_{2}$ in HSV strips, is much lower than previous in vitro studies, which reported that higher concentrations of levosimendan (in the micromolar range) required to elicit vasodilation. Mirkhani et al. [16] reported a maximum relaxation of $45.4 \%$ with $10^{-4} \mathrm{M}$ of levosimendan in norepinephrine-induced contraction. Similar to our result with 5-HT induced contraction, they observed no relaxation with $10^{-8} \mathrm{M}$ of levosimendan in HSV precontracted with norepinephrine. In another study, levosimendan at a concentration of $10^{-8} \mathrm{M}$ did not effect saphenous vein precontracted with 5-HT and the maximum relaxation induced by levosimendan $\left(3 \times 10^{-6} \mathrm{M}\right)$ was $28.1 \pm 7.5 \%$ with an $\mathrm{EC}_{50}$ of $0.32 \pm 0.04$ microM [17].

The present study design does not include the mechanisms of by which levosimendan attenuates $\mathrm{H}_{2} \mathrm{O}_{2}$ induced contractions or cause vasodilation. Previous studies have shown that levosimendan causes positive inotropic and antistunning effects on the heart. This effect was shown to be mediated by calcium sensitization of contractile proteins and vasodilator and antiischemic effects mediated by the opening of ATP-sensitive potassium channels in vascular smooth muscle cells [18]. Levosimendan reduces plasma levels of malondialdehyde, a marker of oxidative stress, in patients with heart failure [19], inhibits $\mathrm{H}_{2} \mathrm{O}_{2}$ induced cardiomyocytes apoptotic cell death by activating $\mathrm{K}_{\text {ATP }}$ channels [20] and preconditioning with levosimendan prevents contractile dysfunction due to $\mathrm{H}_{2} \mathrm{O}_{2}$-induced oxidative stress in human myocardium [21].

Although levosimendan has been shown to induce vasodilatation in human radial and internal mammary arteries and in HSV [22-24], this is the first study considering the effect of levosimendan on $\mathrm{H}_{2} \mathrm{O}_{2}$-induced con- 
traction in HSV.

In conclusion, according to our results we may speculate that pretreatment of HSV with clinical concentrations of levosimendan inhibit the vasoconstriction caused by oxidative stress, indicating its potential preventive effect against oxidative stress induced graft spasm. Further research is warranted to assess the exact mechanisms responsible for this effect of levosimendan.

\section{REFERENCES}

[1] E. Nakamura, N. Tanaka N, M. Kuwabara M, A. Yamashita, Y. Matsuo, T. Kanai, T. Onitsuka, Y. Asada, H. Hisa and R. Yamamoto, "Relative Contributions of 5-Hydroxytryptamine (5-HT) Receptor Subtypes in 5-HT-Induced Vasoconstriction of the Distended Human Saphenous Vein as a Coronary Artery Bypass Graft," Biological \& Pharmaceutical Bulletin, Vol. 34, No. 1, 2011, pp. 82-86. doi: $10.1248 / \mathrm{bpb} .34 .82$

[2] C. A. Hamilton, G. O’Dowd, L. McIntosh, G. Berg, J. Butler, V. Pathi, R. Williams, J. L. Reid and A. F. Dominiczak, "Vasorelaxant Properties of Isolated Human Radial Arteries: Comparison with Internal Mammary Arteries," Atherosclerosis, Vol. 160, No. 2, 2002, pp. 345-353. doi:10.1016/S0021-9150(01)00605-0

[3] S. Attaran, L. John and A. El-Gamel, "Clinical and Potential Use of Pharmacological Agents to Reduce Radial Artery Spasm in Coronary Artery Surgery," The Annals of Thoracic Surgery, Vol. 85, No. 4, 2008, pp. 1483-1489. doi:10.1016/j.athoracsur.2007.10.042

[4] J. T. Parissis, I. Andreadou, S. L. Markantonis, V. Bistola, A. Louka, A. Pyriochou, I. Paraskevaidis, G. Filippatos, E. K. Iliodromitis and D. T. Kremastinos, "Effects of Levosimendan on Circulating Markers of Oxidative and Nitrosative Stress in Patients with Advanced Heart Failure," Atherosclerosis, Vol. 195, No. 2, 2007, pp. 210-215. doi:10.1016/j.atherosclerosis.2007.07.011

[5] K. H. Konz, M. Haap, K. E. Hill, R. F. Burk and R. A. Walsh, "Diastolic Dysfunction of Perfused Rat Hearts Induced by Hydrogen Peroxide. Protective Effect of Selenium," Journal of Molecular and Cellular Cardiology, Vol. 21, No. 8, 1989, pp. 789-795. doi:10.1016/0022-2828(89)90718-9

[6] M. A. Rodriguez-Martinez, E. C. Garcia-Cohen, A. B. Baena, R. Gonzalez, M. Salaices and J. Marin, "Contractile Responses Elicited by Hydrogen Peroxide in Aorta from Normotensive and Hypertensive Rats. Endothelial Modulation and Mechanism Involved," British Journal of Pharmacology, Vol. 125, No. 6, 1998, pp.1329-1335. doi:10.1038/sj.bjp.0702200

[7] Z. W. Yang, T. Zheng, A. Zhang, B. T. Altura and B. M. Altura, "Mechanisms of Hydrogen Peroxide-Induced Contraction of Rat Aorta," European Journal of Pharmacology, Vol. 344, No. 2-3, 1998, pp. 169-181. doi:10.1016/S0014-2999(97)01576-8

[8] A. S. Sahin, E. A. Atalik, T. K. Sahin and N. Doğan, "Cooling and Response to Hydrogen Peroxide in Human Saphenous Vein: Role of the Endothelium," Fundamental
\& Clinical Pharmacology, Vol. 19, No. 3, 2005, pp. 341346. doi:10.1111/j.1472-8206.2005.00330.x

[9] K. Watanabe, Y. Okatani and Y. Sagara, "Potentiating Effect of Hydrogen Peroxide on the Serotonin-Induced Vasocontraction in Human Umbilical Artery," Acta Obstetricia et Gynecologica Scandinavica, Vol. 75, No. 9, 1996, pp. 783-789. doi:10.3109/00016349609054704

[10] J. T. Parissis, I. Andreadou, V. Bistola, I. Paraskevaidis, G. Filippatos and D. T. Kremastinos, "Novel Biologic Mechanisms of Levosimendan and Its Effect on the Failing Heart," Expert Opinion on Investigational Drugs, Vol. 17, No. 8, 2008, pp. 1143-1150. doi:10.1517/13543784.17.8.1143

[11] R. S. Barlow, A. M. El-Mowafy and R. E. White, " $\mathrm{H}_{2} \mathrm{O}_{2}$ Opens $\mathrm{BK}_{\mathrm{ca}}$ Channels via the $\mathrm{PLA}_{2}$-Arachidonic Acid Signaling Cascade in Coronary Artery Smooth Muscle," American Journal of Physiology: Heart and Circulatory Physiology, Vol. 279, No. 2, 2000, pp. H475-H483.

[12] T. Suvorava, N. Lauer, S. Kumpf, R. Jacob, W. Meyer and G. Kojda, "Endogenous Vascular Hydrogen Peroxide Regulates Arteriolar Tension in Vivo," Circulation, Vol. 112, No. 16, 2005, pp. 2487-2495.

doi:10.1161/CIRCULATIONAHA.105.543157

[13] A. Hara, T. Suızuki, H. Hashizume, N. Shishido, M. Nakamura, F. Ushikubi and Y. Abiko, "Effects of CP-060S, a Novel $\mathrm{Ca}^{2+}$ Channel Blocker, on Oxidative Stress in Cultured Cardiac Myocytes," European Journal of Pharmacology, Vol. 385, No. 1, 1999, pp. 81-88. doi:10.1016/S0014-2999(99)00708-6

[14] S. Shimizu, Y. Saitoh, T. Yamamoto and K. Momose, "Stimulation by Hydrogen Peroxide of L-Arginine Metabolism to L-Citrulline Coupled with Nitric Oxide Synthesis in Cultured Endothelial Cells," Research Communications in Chemical Pathology Pharmacology, Vol. 84, No. 3, 1994, pp. 315-329.

[15] Z. W. Yang, T. Zheng, J. Wang, A. Zhang, B. T. Altura and B. M. Altura, "Hydrogen Peroxide Induces Contraction and Raises $\left[\mathrm{Ca}^{2+}\right] \mathrm{i}$ in Canine Cerebral Arterial Smooth Muscle: Participation of Cellular Signaling Pathways," Naunyn-Schmiedeberg's Archives of Pharmacology, Vol. 360, No. 6, 1999, pp. 646-653. doi:10.1007/s002109900128

[16] H. Mirkhani, M. Shafa and H. Khazraei, "Comparison of the Effects of Levosimendan and Papaverine on Human Internal Mammary Artery and Saphenous Vein," Cardiovascular Drugs and Therapy, Vol. 23, No. 5, 2009, pp. 355-359. doi:10.1007/s10557-009-6197-0

[17] E. P. Sandell, M. Hayha, S. Antila, P. Heikkinen, P. Ottoila, L. A. Lehtonen and P. J. Pentikainen, "Pharmacokinetics of Levosimendan in Healthy Volunteers and Patients with Congestive Heart Failure," Journal of Cardiovascular Pharmacology, Vol. 26, Supplement 1, 1995, pp. 557-562.

[18] G. Lilleberg, S. Sundberg and M. S. Nieminen, "Doserange Study of a New Calcium Sensitizier, Levosimendan, in Patients with Left Ventricular Dysfunction," Journal of Cardiovascular Pharmacology, Vol. 26, Supplement 1, 1995, pp. S563-S569. 
[19] O. Pollesello and Z. Papp, "The Cardioprotective Effects of Levosimendan: Preclinical and Clinical Evidence," Journal of Cardiovascular Pharmacology, Vol. 50, No. 3, 2007, pp. 257-263. doi:10.1097/FJC.0b013e3180986230

[20] C. Avgeropoulou, I. Andreadou, S. Markantonis-Kyroudis, M. Demopoulou, P Missovoulos, A. Androulakis and I. Kallikazaros, "The $\mathrm{Ca}^{2+}$-Sensitizer Levosimendan Improves Oxidative Damage, BNP and Pro-Inflammatory Cytokine Levels in Patients with Advanced Decompensated Heart Failure in Comparison to Dobutamine," European Journal of Heart Failure, Vol. 7, No. 5, 2005, pp. 882-887. doi:10.1016/j.ejheart.2005.02.002

[21] D. M. Kopustinskiene, P. Pollesello and N. E. Saris, "Levosimendan is a Mitochondrial $\mathrm{K}_{\mathrm{ATP}}$ Channel Opener," European Journal of Pharmacology, Vol. 428, No. 3, 2001, pp. 311-314. doi:10.1016/S0014-2999(01)01350-4
[22] A. S. Sahin, N. Gormus and A. Duman, "Preconditioning with Levosimendan Prevents Contractile Dysfunction Due to $\mathrm{H}_{2} \mathrm{O}_{2}$-Induced Oxidative Stress in Human Myocardium," Journal of Cardiovascular Pharmacology, Vol. 50, No. 4, 2007, pp. 419-423. doi:10.1097/FJC.0b013e318123fbf9

[23] J. Pataricza, J. Szolnoky, I. Krassoi, Z. Hegedus, A. Kun, A. Varro and J. G. Papp, "Vazorelaxing Effect of LevosiMendan against 5-Hydroxytryptamine-Induced Contractions in Isolated Human Conduit Bypass Grafts," Journal of Pharmacy and Pharmacology, Vol. 58, No. 8, 2006, pp. 1107-1112. doi: $10.1211 /$ jpp.58.8.0012

[24] J. Hohn, J. Pataricza and A. Petri, "Levosimendan Interacts with Potassium Channel Blockers in Human Saphenous Veins," Basic \& Clinical Pharmacology \& Toxicology, Vol. 94, No. 6, 2004, pp. 271-273. 